number of pressure peaks $>50 \mathrm{mmHg}$ was 64.66 per patient with saline irrigation compared with 0.33 per patient with isoproterenol.

The authors conclude that relaxation of the ureter with a $\beta$-adrenoceptor agonist during ureterorenoscopy reduces renal pelvic pressure; maintaining pelvic pressure below the threshold for intrarenal backflow ( 30$45 \mathrm{mmHg}$ ) may help to prevent complications such as sepsis.

Original article Jung H et al. (2008) Endoluminal isoproterenol irrigation decreases renal pelvic pressure during flexible ureterorenoscopy: a clinical randomized, controlled study. Eur Urol 54: 1404-1413

\section{A new home test to detect low concentrations of sperm after vasectomy}

Poor compliance with postvasectomy semen analysis (to determine whether residual sperm have been cleared from the reproductive tract) is attributed to patient embarrassment with regard to providing semen samples, and the inconvenience of returning to the clinic. A home testing kit could, therefore, improve patient compliance. Klotz and colleagues report on clinical and consumer testing of a lateral flow immunochromatographic diagnostic device, SpermCheck ${ }^{\circledR}$ Vasectomy (ContraVac, Inc., Charlottesville, VA), which can detect sperm at concentrations of 250,000 sperm per $\mathrm{ml}$ of semen or greater.

A total of 144 semen samples were collected from 100 patients who underwent vasectomy; all samples were tested with SpermCheck ${ }^{\circledR}$ Vasectomy, and the sperm concentration for each sample was also determined using a hemacytometer. Sperm concentrations $>250,000 / \mathrm{ml}$ were detected by hemacytometer in 40 samples, 37 of which produced a positive result with the SpermCheck ${ }^{\circledR}$ device (93\% sensitivity). The concentrations of the three samples with false-negative results were all $<385,000 / \mathrm{ml}$ (some investigators suggest that concentrations $<1,000,000 / \mathrm{ml}$ indicate postvasectomy sterility). Negative test results were recorded for 101 of the 104 samples with sperm concentrations less than $250,000 / \mathrm{ml}$ (97\% specificity).

Consumer studies revealed that the diagnostic test has 98\% agreement with hemacytometer results, and could achieve the same results whether carried out by home users or laboratory personnel.

The authors conclude that SpermCheck ${ }^{\circledR}$ Vasectomy, which is approved by the US FDA, is a simple yet sensitive home test that will potentially improve compliance with postvasectomy semen analysis.

Original article Klotz KL et al. (2008) Clinical and consumer trial performance of a sensitive immunodiagnostic home test that qualitatively detects low concentrations of sperm following vasectomy. J Urol 180: 2569-2576

\section{New GnRH antagonist rapidly suppresses testosterone and PSA}

Klotz et al. have compared the efficacy and safety of degarelix, a new gonadotropinreleasing hormone $(\mathrm{GnRH})$ antagonist, with leuprolide, a $\mathrm{GnRH}$ receptor agonist, in a phase III study of men with prostate cancer.

A total of 610 patients (median age 73 years) participated in the 12-month, active-controlled, open-label, randomized trial. Patients received either a monthly $7.5 \mathrm{mg}$ dose of leuprolide (intramuscular injection, 201 men) or one of two degarelix regimens: subcutaneous injection of $240 \mathrm{mg}$ in month 1 , followed by a maintenance dose of either $80 \mathrm{mg}$ or $160 \mathrm{mg}$ every month for 11 months (207 and 202 patients, respectively).

Sustained reduction of testosterone levels from baseline (median $3.9 \mathrm{ng} / \mathrm{ml}$ ) to $0.5 \mathrm{ng} / \mathrm{ml}$ or less was achieved by $96.4 \%, 97.2 \%$ and $98.3 \%$ of patients in the leuprolide, degarelix $240+80 \mathrm{mg}$ and degarelix $240+160 \mathrm{mg}$ groups, respectively. Both degarelix doses reduced testosterone and PSA levels more rapidly than leuprolide; a transient $65 \%$ surge in testosterone concentration was observed in the leuprolide group at day 3. Maintenance of testosterone suppression was comparable for both drugs, and all three regimens were well tolerated.

Klotz and colleagues conclude that degarelix is an effective androgen deprivation therapy that does not induce the initial testosterone flare associated with $\mathrm{GnRH}$ receptor agonists, eliminating the need for antiandrogen supplementation.

Original article Klotz L et al. (2008) The efficacy and safety of degarelix: a 12-month, comparative, randomized, openlabel, parallel-group phase III study in patients with prostate cancer. BJU Int 102: 1531-1538 